\title{
GROUNDMASS ISOTOPE SIGNATURES REVEAL DECADAL SOURCE EVOLUTION AND MIXING AT MOUNT ETNA
}

\author{
RUADHAN MAGEE ${ }^{1}$, TERESA UBIDE ${ }^{1}$, JOHN \\ CAULFIELD $^{2}$ AND JIAN-XIN ZHAO ${ }^{1}$
}

${ }^{1}$ The University of Queensland

${ }^{2}$ Queensland University of Technology

Presenting Author: ruadhan.magee@uq.edu.au

Mount Etna (Italy), one of the most active volcanoes on Earth, has seen an increase in eruptive frequency and explosivity since 1970 that has been linked to an abrupt shift in magma composition [1]. Here we explore the compositional evolution of erupted melts via analysis of groundmass separates. We measure trace elements and isotopes ( $\mathrm{Sr}-\mathrm{Nd}-\mathrm{Pb}-\mathrm{Hf}$ ) in a suite of carefully hand-picked groundmass separates from both historic (pre-1970) and recent (1974-2014) eruptions to minimise the effects of crystal inheritance, and compare the results to literature wholerock data.

Between 1992 and 2003, groundmass was significantly more radiogenic than its corresponding mineral cargo, whilst whole rock compositions were intermediate. Our findings indicate that resident crystal mushes are often isotopically distinct from the magmas in which they are entrained. Groundmass compositions, undiluted by historic crystal signatures, can therefore provide an accurate record of magma chemistry through time.

Groundmass isotope data supports the abrupt change in composition from historic to recent eruptions. The two most opposing isotopic compositions in groundmass are from the 1566 and 2002-03 S-rift eruptions. We consider these compositions the best approximations of pre-and post-1970 compositional endmembers. A binary mixing model between these two endmembers reproduces most of the compositional variability throughout the period 1566-2014.The Sr-Nd-Pb-Hf systematics of groundmass suggest that these melts are derived from variable addition of EM1 (15-25\%) to FOZO-type mantle source. Post1970 , the shift towards higher ${ }^{87} \mathrm{Sr} /{ }^{86} \mathrm{Sr}$ and lower ${ }^{143} \mathrm{Nd} /{ }^{144} \mathrm{Nd}$, ${ }^{176} \mathrm{Hf} /{ }^{177} \mathrm{Hf}$, and ${ }^{206} \mathrm{~Pb} /{ }^{204} \mathrm{~Pb}$ values may reflect increased melting of EM1 metasomatic phases, as suggested by previous authors.

However, not all groundmass isotopic signatures can be attributed to melting of heterogeneous mantle. Enrichments in ${ }^{207} \mathrm{~Pb} /{ }^{204} \mathrm{~Pb}$ and ${ }^{208} \mathrm{~Pb} /{ }^{204} \mathrm{~Pb}$ occur independently from all other isotopes and only in some of Etna's most explosive historic eruptions (1669, 1974 and 2002-03 S-rift). Bulk addition of 4-5\% radiogenic sediment (radiolarian clay; White et al., 1985) to the EM1 enriched FOZO-mantle source can reproduce the observed trends. The potential link between isotope enrichment and explosive eruptions opens an exciting avenue for further investigation. 